\title{
BRAZILIAN VERSION OF THE “PRIMARY SJÖGREN SYNDROME - QUALITY OF LIFE QUESTIONNAIRE (PSS-QOL)"
}

Ana Paula Truhlar Pedrini ${ }^{1}$, Bianca Domingos Noronha ${ }^{1}$, Pedro Henrique Alves dos Santos ${ }^{1}$, Letícia Fonseca Favarato ${ }^{1}$, Luíza Vallory Alochio ${ }^{1}$, Weider Andrade Tomé ${ }^{1}$, Érica Vieira Serrano ${ }^{1}$, Maria Bernadete Renoldi de Oliveira Gavi ${ }^{1}$, Ana Paula Espíndula Gianórdoli ${ }^{1}$, Valéria Valim ${ }^{1}$, Samira Tatiyama Miyamoto ${ }^{1, *}$

1.Universidade Federal do Espírito Santo, Vitória (ES), Brazil.

*Corresponding author: sa.miyamoto@hotmail.com

\section{BACKGROUND}

Primary Sjögren's syndrome (pSS) is a chronic autoimmune systemic disease characterized by a lymphocytic infiltration into the exocrine glands, causing dryness in the mouth and eyes. In addition, most patients report fatigue and pain, and some may have systemic manifestations, leading to impaired quality of life. The "Primary Sjögren's Syndrome Quality of Life (PSS-QoL)" questionnaire is the first specific instrument to assess quality of life in pSS1. The purpose of this study was to translate the PSS-QoL for the Brazilian Portuguese language and carry out its cross-cultural adaptation.

\section{MATERIALS AND METHODS}

The original version was submitted for translation into Portuguese by two native Brazilian speakers fluent in English after the objective of the study was explained to them. A committee, composed of two physiotherapists and two physicians with proficiency of the English language and the disease, analyzed the two translations and generated the first version in the Brazilian Portuguese language. This version was subjected to back-translation into English by two other two English speakers whose native language was English and who were unaware of the original version of the objective of the study. The committee compared the two backtranslated versions with the original version and no relevant differences were found. The first final version in Brazilian Portuguese was submitted to the cross-cultural adaptation. Twenty-five participants with pSS responded to the questionnaire in phase I. Items with more than $15 \%$ incomprehension were modified and another 25 participants responded to the questionnaire in phase II.

\section{RESULTS}

The first version in the Portuguese language obtained after translation, back translation and analysis by the committee was considered the first version in the Brazilian Portuguese language and the one that was submitted to the cross-cultural adaptation. In the cross-cultural adaptation phases, $85 \%$ were women, with an average age of $57( \pm 12.3)$ and 51 ( \pm 15.8$)$ years in cross-cultural adaptation phases I and II, respectively. In phase I, 8 questions and 1 answer item were rewritten due to incomprehension by the first 25 participants and were subsequently submitted to phase II for application to another 25 participants, when all questions had less than $15 \%$ of doubts.

\section{CONCLUSION}

The questionnaire was translated and cross-culturally adapted, generating the Brazilian version of the PSS-QoL. The validation and reliability study are already been conducted.

\section{REFERENCE}

1. Lackner A, Stradner MH, Hermann J, Unger J, Stamm T, Graninger WB, Dejaco C. Assessing health-related quality of life in primary Sjögren's syndrome-The PSS-QoL. Semin Arthritis Rheum. 2018;48(1):105-110. https://doi.org/10.1016/j.semarthrit.2017.11.007 